\title{
Unusual Posterior Traumatic Hip Dislocations at Yopougon/Abidjan Teaching Hospital
}

\author{
Alidou Traoré1 ${ }^{*}$, Leopold Koffi Krah', Daouda Kanaté Soumaro', Rebecca Eva Boka ${ }^{1}$, \\ Christelle Mobiot-Aka1, Alban Slim Mbende², Mamadou Dosso'1, Kader Sy', \\ Jean Baptiste Sie Essoh', Insa Bamba1, Yves Lambin'1 \\ ${ }^{1}$ Trauma and Orthopaedic Surgery Unit, Yopougon Teaching Hospital, Abidjan, Ivory Coast \\ ${ }^{2}$ Neurosurgery Unit, Yopougon Teaching Hospital, Abidjan, Ivory Coast \\ Email: "tralidou@yahoo.fr
}

Received 16 February 2016; accepted 11 April 2016; published 14 April 2016

Copyright (C) 2016 by authors and Scientific Research Publishing Inc.

This work is licensed under the Creative Commons Attribution International License (CC BY). http://creativecommons.org/licenses/by/4.0/

(c) $\underset{\mathrm{EY}}{\mathrm{B}}$ Open Access

\begin{abstract}
Traumatic dislocation of the hip is quite rare and accounts for $2 \%-5 \%$ of all dislocations. We report on a case of a bilateral posterior hip dislocation associated with symmetric acetabular fracture and two cases of infracotyloid dislocation. The report included 2 men and one woman. The mean age of patients was 33 years. All dislocations followed a road traffic accident. Non-operative closed reduction was achieved within 19 hours of admission. The average follow-up time was 15 months. The hips were stable, mobile, and painless; and there was no radiographic sign of avascular necrosis of the femoral head.
\end{abstract}

\section{Keywords}

Hip, Dislocation, Posterior, Infracotyloid, Posterior Wall

\section{Introduction}

Traumatic dislocations of the native hip are relatively rare injuries resulting from high-energy mechanisms producing grossly abnormal force vectors acting across the hip joint. It is quite rare and accounts for $2 \%-5 \%$ of all dislocations [1] [2]. Traumatic posterior bilateral hip dislocations and infracotyloid dislocation are very rare injuries and less frequently associated with fractures of the hip joint, and occur in poly-traumatic contexts [1]-[6]. Posterior dislocation of the hip is an orthopaedic emergency. Non-operative closed reduction is the treatment of

${ }^{*}$ Corresponding author.

How to cite this paper: Traoré, A., Krah, L.K., Soumaro, D.K., Boka, R.E., Mobiot-Aka, C., Mbende, A.S., Dosso, M., Sy, K., Essoh, J.B.S., Bamba, I. and Lambin, Y. (2016) Unusual Posterior Traumatic Hip Dislocations at Yopougon/Abidjan Teaching Hospital. Open Journal of Orthopedics, 6, 71-77. http://dx.doi.org/10.4236/ojo.2016.64011 
choice for this injury [1] [3] [7]-[9]. Their prognosis is mainly functional and linked to femoral head avascular necrosis and coxarthrosis [10]-[13]. We report on one case of a bilateral posterior hip dislocation associated with symmetric acetabular fracture and two cases of infracotyloid dislocation.

\section{Observations}

\subsection{Observation 1}

Mrs. NL was a 49-year-old patient, with no medical history, who was referred to us the 20 September 2004 by the military fire-fighting team for the management of multiple injuries following a road traffic accident. In the circumstances of the accident, she was a passenger of a car which lost control and collided with a tree. Clinical examination on arrival revealed a bilateral adduction, internal rotation and extension at the hip. Anteroposterior plain radiography of the pelvis and standard $\mathrm{x}$-ray of the hips demonstrated a bilateral iliac dislocation associated with a bilateral posterior wall fracture (Figure 1). Reduction was performed under general anaesthetics 48 hours after the accident. Reduction was stable and control radiography revealed a satisfying reduction of dislocations (Figure 2). The patient benefitted of 3 weeks of bilateral skeletal bed tractions, followed by 4 weeks of restricted weight-bearing. Full weight-bearing was authorised from the 8th week. After 18 months follow-up, there was no radiological sign of femoral head necrosis.

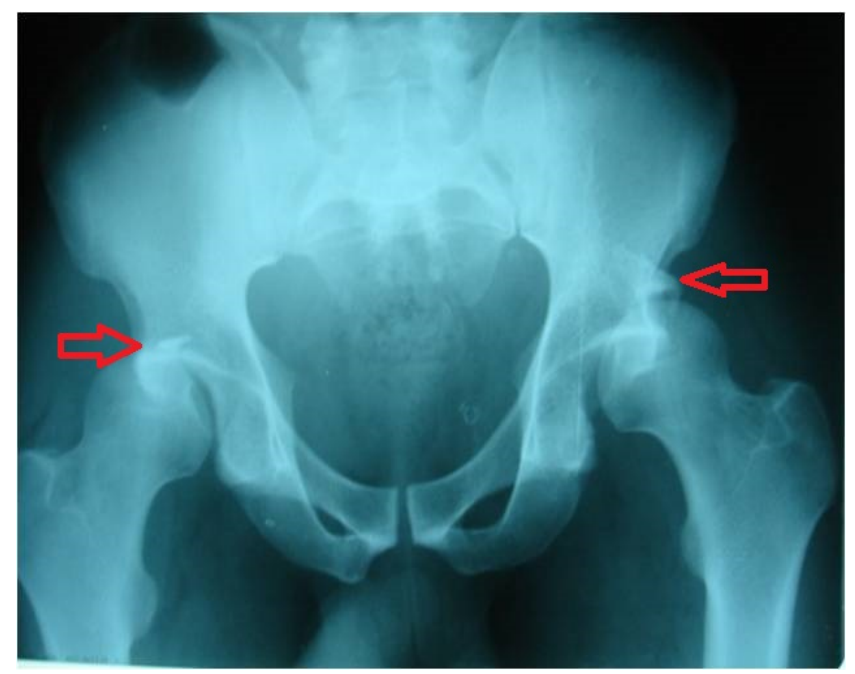

Figure 1. AP radiograph of the pelvis, demonstrating bilateral posterior dislocation. The red arrow indicates the bilateral symmetric acetabular fracture.

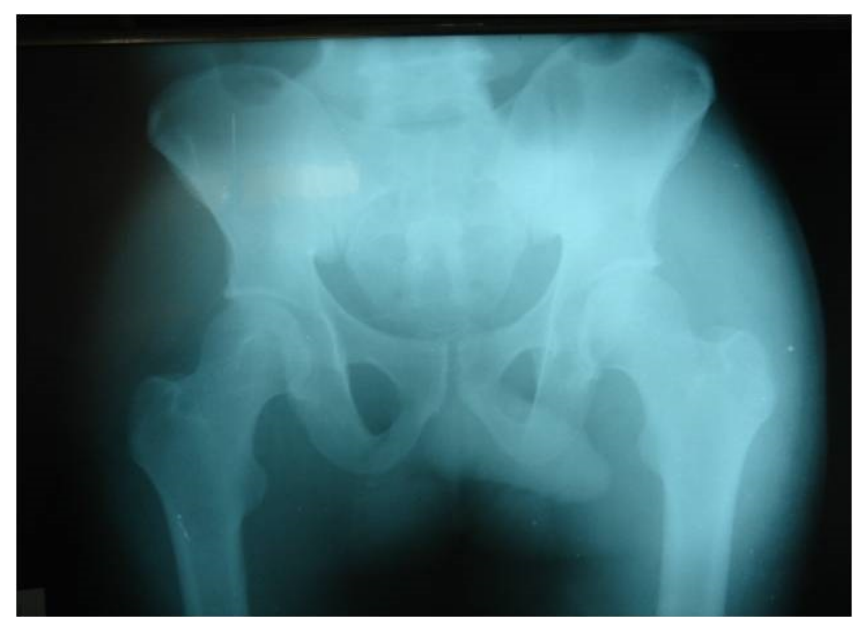

Figure 2. Anteroposterior radiograph of the pelvis with satisfying reduction of dislocations. 


\subsection{Observation 2}

GA was 23 with no medical history, when he was referred to us the 24 January 2004 by the military fire-fighting team for the management of multiple injuries following a road traffic accident. In the circumstances of the accident, the patient was drunk when he was hit and run over by a taxi driver. Clinical examination revealed flexion, adduction and internal rotation at the hip; and multiple wounds and dermabrasions. Plain radiography demonstrated an infracotyloid dislocation (Figure 3). He underwent reduction under general anaesthetics in Accident and Emergency Unit 7 hours after the accident. The hip was stable and pelvic anteroposterior x-ray revealed a satisfying reduction with congruence (Figure 4). The patient benefitted from a 10-day skeletal bed traction. He was discharged on the 3 February 2004 with one week restricted weight-bearing. He was partially weight-bearing by the 3rd week and full weight-bearing by the 5th week. Sixteen months after the accident, he was re-assessed and the hip was mobile and painless.

\subsection{Observation 3}

KAK was a 27-year-old patient with no medical history, who was referred to us the 15 December 2012 by the

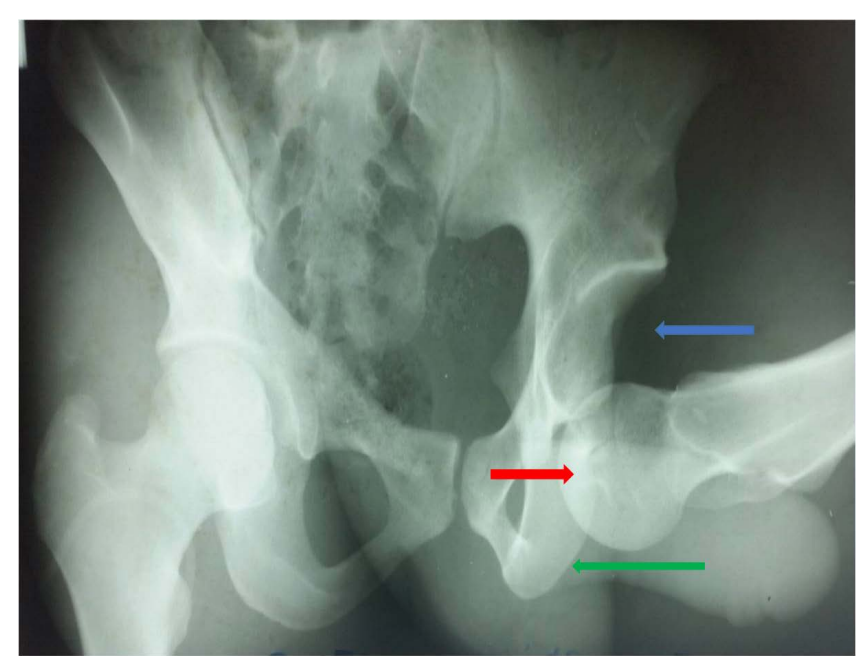

Blue arrow indicates acetabular emptiness;

Red arrow indicates the infracotyloid position of the head;

Green arrow indicates the ischium.

Figure 3. Anteroposterior radiograph of the pelvis, demonstrating an infracotyloid dislocation (patient 2).

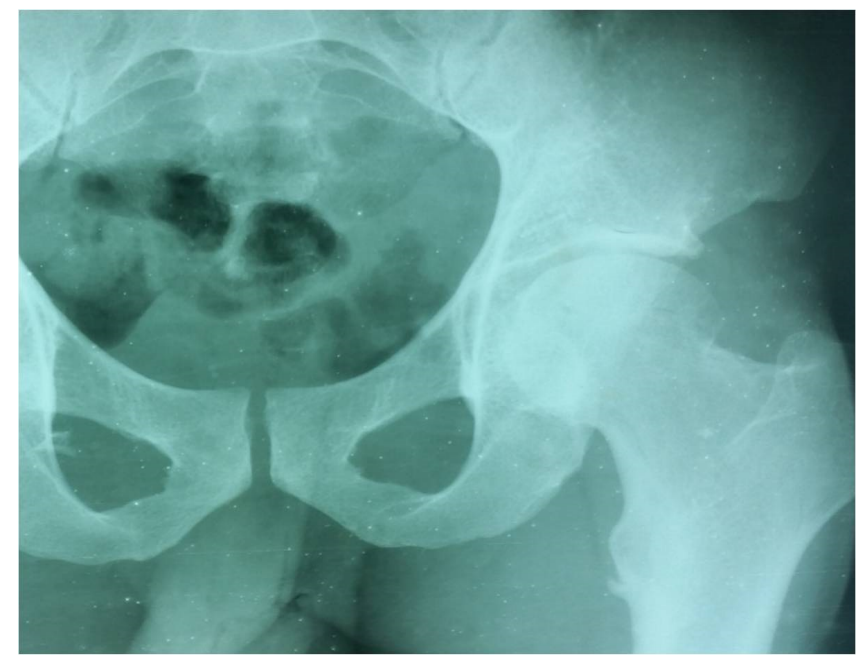

Figure 4. Anteroposterior radiograph of the pelvis with satisfying reduction of dislocations. 
military fire-fighting team for a right hip injury following a road traffic accident. The lorry driver patient lost control of his lorry, and as result, the lorry rolled over many times. Clinical examination revealed flexion, adduction and internal rotation at the hip. X-ray images concluded to an infracotyloid dislocation (Figure 5). Reduction was performed under general anaesthetics 12 hours after the accident. The hip was stable and pelvic anteroposterior radiography demonstrated a satisfying reduction with congruence. He benefitted from a15-day skeletal bed traction. The patient attended 2 out-patient appointments in 6 months interval. After 12 months follow-up, there was no radiological sign of femoral head necrosis.

The summary of patients' observations is included in Table 1. Informed consent from patients was sought and obtained.

\section{Discussion}

Traumatic dislocation of the normal hip joint is rare because of its deep acetabular cavity and strong surrounding ligamentous structures. The posteroinferior capsule is the hip's weakness area. As a result, posterior dislocations are frequent compared to anterior ones.Ninety per cent of dislocations are posterior, occurring as a result of high-energy transfer, mostly in car and motorcycle accidents $46 \%$ and $18 \%$ respectively [1] [2] [7] [14] [15]. This results when a sufficient force is applied in the long axis of the femoral shaft while the hip is flexed and adducted. Traumatic dislocation of the hip is quite rare and accounts for $2 \%-5 \%$ of all dislocations [1] [3].

The mechanism of posterior dislocations is forced adduction, internal rotation, and some degree of flexion of the hip. Whether a hip dislocation occurs with or without a fracture of the acetabulum is largely dependent on the direction of the femoral head at the time of injury. Increased flexion and adduction is more likely to cause a simple dislocation. Femoral anteversion may predispose patients to simple hip dislocations [1] [2] [9] [15]. Dashboard mechanism is the most common; and a posterior lumbar impact on a squatted patient is rarely reported [1] [5] [14] [15]. According to the degree of hip flexion, the dislocation might be iliac (50\%) or ischial $(15 \%)$. The classic appearance of posterior hip dislocation is a leg that is flexed, internally rotated, adducted, and

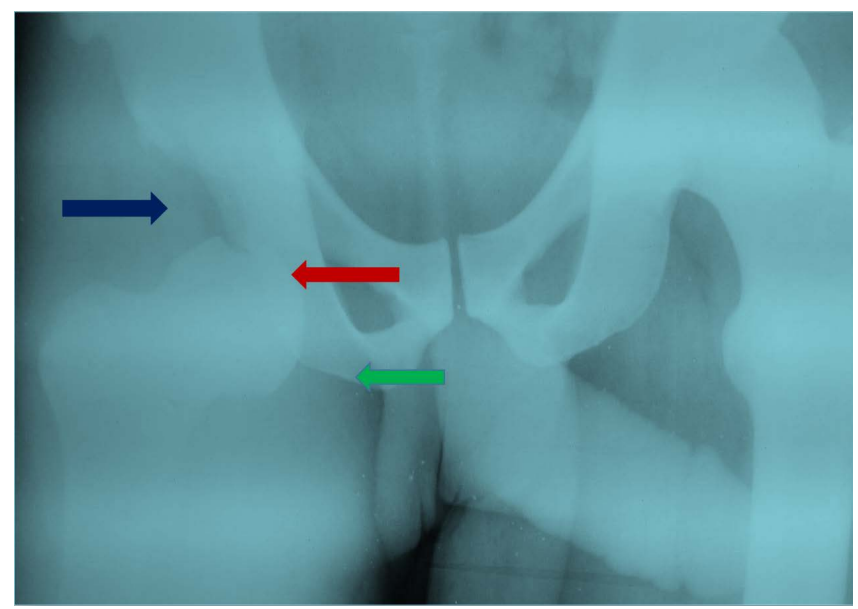

Blue arrow indicates acetabular emptiness;

Red arrow indicates the infracotyloid position of the head;

Green arrow indicates the ischium.

Figure 5. Anteroposterior radiograph of the pelvis, demonstrating an infracotyloid dislocation (patient 3).

Table 1. Comparative table of the three dislocations.

\begin{tabular}{|c|c|c|c|c|c|c|c|c|}
\hline Patients & Age & Sex & Etiology & $\begin{array}{l}\text { Dislocation } \\
\text { type }\end{array}$ & $\begin{array}{l}\text { Associated } \\
\text { lesions }\end{array}$ & $\begin{array}{l}\text { Reduction time } \\
\text { (hours) }\end{array}$ & $\begin{array}{l}\text { Follow up } \\
\text { (months) }\end{array}$ & Results \\
\hline 1 & 49 & $\mathrm{~F}$ & RTA $^{*}$ & $\begin{array}{l}\text { posterior } \\
\text { bilateral }\end{array}$ & $\begin{array}{c}\text { symmetric } \\
\text { posterior wall }\end{array}$ & 48 & 18 & hip mobile, painless and no head necrosis \\
\hline 2 & 23 & M & RTA $^{*}$ & infracotyloid & none & 7 & 16 & hip mobile, painless and no head necrosis \\
\hline 3 & 27 & M & RTA $^{*}$ & infracotyloid & none & 12 & 12 & hip mobile, painless and no head necrosis \\
\hline
\end{tabular}

${ }^{*}$ Road Traffic Accident. 
foreshortened [1] [2] [5] [14] [16].

Traumatic bilateral hip dislocation is an extremely uncommon injury and rarely seen in children. It's a rare condition that always occurs as a result of a high-energy trauma and is associated with a $4 \%$ mortality rate [1] [9] [15]-[17]. Bilateral posterior traumatic dislocation of the hip associated with fracture of the posterior acetabular wall is a common and extensively described lesion. There have been few documented cases in the literature [18]. Nonetheless some diagnostic and therapeutic issues are still debated. The diagnostic aspects essentially involve the precise identification of lesion type, due to the limitations of conventional radiography. The diffusion of CT, which provides greater information about fracture characteristics, degree of fragment displacement, acetabular impaction and number and size of intra-articular fragments, has largely solved this problem [1] [9] [15]-[18].

Compound types (posterior or anterior) or asymmetric, account for $40 \%$ of all cases of bilateral dislocations. In these instances, the posterior dislocation follows a classic dashboard impact, whereas the anterior one, an impact on the medial side of the knee with a flexion at the hip [17].

Inferior dislocation of hip or luxatio erecta femoris is the rarest among all types of hip dislocations. It can be caused by a severe trauma to the hip and the mechanism of injury is intriguing. Very few cases have been reported. Most of the earlier reported cases involved the pediatric age group [3] [6] [19]. When the hip dislocates inferiorly, it is flexed to an extent that the distal end of the femur rises above the horizontal plane of the pelvis at the acetabular fossae level. The exact sequence of events resulting in the deformity is not always remembered [3] [6] [19].

The striking deformity of the limb makes the diagnosis easy in Accident and Emergency Unit. It is important to examine the patient for sciatic nerve palsy before reducing the dislocation. In the presence of such a condition, the patient has to be followed up with periodic EMG study at 1 and 5 months to determine the severity of the injury and eventual surgical treatment [20].

Diagnostic imaging is an extremely important tool in diagnosing and treating hip dislocations. A simple anteroposterior view of the pelvis is usually all that is needed to diagnose a hip dislocation. There is a frequent association with osteoarticular lesions, osteochondral femoral head fractures being the most common. A Computerized Tomography (CT) must be warranted to confirm those lesions, reveal intra-articular incarcerated fragments and better appreciate any association with a pelvic brim fracture as in one of our patients [2] [13] [14] [21].

Traumatic hip dislocations are orthopaedic emergencies which require immediate attention, so to enhance the functional prognosis. The incidence of avascular necrosis is directly related to the time the hip remains dislocated and is significantly reduced if reduction is done within 6 hours. All dislocations were treated with closed reduction under general anesthetics, with an average of 28 hours, followed by varying regimens of skeletal traction and restricted weight-bearing.

Surgical reduction is warranted if closed reduction fails. Hip stability testing following reduction is paramount; so is the success of reduction which needs to be appreciated by control fluoroscopy and plain radiography. These often contradictory clinical and experimental data led us to extend the surgical indication to all fractures involving $>20 \%$ of the posterior wall, even stable ones; those with a gap $>2 \mathrm{~mm}$ and a step of $1 \mathrm{~mm}$ on $\mathrm{CT}$; and those with acetabular impaction and/or one or more intraarticular fragments [5] [7] [10].

Apart from life threatening injuries, dislocation reduction should take precedence over treatment of all other skeletal injuries [2].

The post-reduction regimen following a closed reduction of a simple hip dislocation is controversial. There is no consensus in the literature about the non-weight-bearing period. Endo et al. [9] resumed weight-bearing 6 weeks following reduction. Glass and Powell [22] believe that a non-weight-bearing period is not related to the outcome, but, since in some of the reported cases there was evidence of synovial irritation many weeks after injury, it would appear that weight-bearing should not be attempted for a minimum of two to three weeks. In our case we had resumed partial weight-bearing after 3 weeks and full weight-bearing in 6 week. Our average skeletal traction time ranged from 10 to 15 days, with an exception of the patient with posterior luxation, where the traction lasted 3 weeks. To our knowledge, there are no prospective studies proving that non-weight bearing decreases the development of avascular necrosis.

A combined symmetric fracture of the posterior wall prohibited progressive weight-bearing in one patient after 3 weeks of skeletal traction, as advocated by Dawson and Van Rijin [8]. The attitude in these cases will depend on associated lesions [1] [18] [23].

All patients eventually achieved a full and pain-free range of hip motion, with no evidence of avascular ne- 
crosis of the femoral head.

Avascular necrosis is the most common risk and is frequently reported in posterior dislocation. Simple hip dislocations have significant long-term complications, avascular necrosis of the femoral head, early degenerative osteoarthritis, nerve injury, and heterotopic ossification. Simple posterior dislocations are often associated with acetabular fractures and have a worse prognosis than anterior dislocations without femoral head fractures [13]. Hip dislocation with bilateral acetabular fracture is rare and serious lesion. Patients need to be followed up for a long time as complications can surface some time.

Although avascular necrosis of the femoral head, is generally thought to occur within 2 years after hip dislocation, a recent report noted avascular necrosis of the femoral head, of the femoral head 8 years after a posterior hip dislocation [10]. However, recent studies suggest that avascular necrosis results from the initial injury not from a prolonged dislocation though prompt reduction is still vital [14].

Factors which influence the outcome include the extent of other severe injuries, the time of reduction which should be within 6 hours post-traumatic, the direction of the dislocation, and the overall condition of the patient prior to dislocation [2] [5] [7] [10] [11] [14]. Its prognosis depends on the initial injury and subsequent treatments. Hougaard and Thomsen [12] reported a $4.8 \%$ incidence of avascular necrosis of the femoral head when reduction occurred within 6 hours compared to a 58.8\% incidence when it was performed after 6 hours. We did not record any avascular necrosis in our series. This should be interpreted, however, with precautions; since the follow-up time had been very short. Avascular necrosis is suspected on clinical grounds, and confirmed on a standard radiography. Computerized Tomography (CT) and Magnetic Resonance Imaging (MRI) are used to evaluate precisely the extent and level of lesions and to determine the size and location of necrosis, so that the surgeon could discuss a possible indication of a conservative treatment which may delay a total hip prosthetic reconstruction in these younger patients [1] [10] [18]. Clinical and radiological evidence of avascular necrosis will take at least 17 months before being noticed. A minimum follow-up of two years is required before reviewing the long term outcome; such as femoral head avascular necrosis, peri-articular ossifications and coxarthrosis [1] [3] [7] [10]-[13] [18].

This case presented an unusual, severe combination of injuries resulting from a high-speed motor-vehicle accident. Traumatic hip dislocation represents a true orthopedic emergency. Given the severity of the associated complications, every effort should be made to ensure prompt diagnosis and immediate therapy.

The follow-up of femoral head necrosis consists of bone scintigraphy or better MRI of the hip [1] [2] [18].

\section{Conclusion}

Inferior dislocation and bilateral posterior hip dislocation associated with symmetric acetabular fracture are extremely rare injuries. Road-traffic collisions are the main causes and the affected patients have a high incidence of associated injuries. Immediate reduction should be attempted before considering operative measures. An optimal outcome is achieved when reduction is achieved within 6 hours, which has been shown to minimize the incidence of ensuing avascular necrosis. Avascular necrosis generally occurs within 2 years of the injury, but it has been reported as up to 5 years post-injury. It is important to counsel patients about the incidence of longterm sequelae, such as avascular necrosis, post-traumatic arthritis and the likely necessity of future interventions. Therefore, an appropriate length of clinical and radiological follow-up should be necessary.

\section{Conflict of Interest}

The authors state that there is no conflict of interest.

\section{References}

[1] Ajay, P.S., Amarjit, S.S. and Arun, P.S. (2010) Traumatic Bilateral Hip Dislocation with Bilateral Sciatic Nerve Palsy. Chinese Journal of Traumatology, 13, 126-128.

[2] Clegg, T.E., Roberts, C.R., Greene, J.W. and Prathe, B.A. (2010) Hip Dislocations. Epidemiology, Treatment, and Outcome. Injury-Internal Journal of the Care Injured, 41, 329-334. http://dx.doi.org/10.1016/j.injury.2009.08.007

[3] Aggarwal, S., Kumar, V., Bhagwat, K.R., Shashikanth, V.S. and Ravikumar, H.S. (2012) Inferior Dislocation of the Hip: A Case Series and Literature Review. Chinese Journal of Traumatology, 15, 317-320.

[4] Bhagwat, K.R., Garg, B., Aggarwal, S. and Dhillon, M.S. (2012) Bilateral Inferior Dislocation of the Hip: A Case Re- 
port. Chinese Journal of Traumatology, 15, 121-123.

[5] Epstein, H.C. (1974) Posterior Fracture-Dislocations of the Hip: Long Term Follow-Up. Journal of Bone \& Joint Surgery, 56, 1103.

[6] Kolar, M.K., Joseph, S. and McLaren, A. (2011) Luxatio Erecta of the Hip. Journal of Bone \& Joint Surgery, 93, 273.

[7] Jacob, J.R., Rao, J.P. and Ciccarelli, C. (1987) Traumatic Dislocation and Fracture Dislocation of the Hip: A Long Term Follow-Up Study. Clinical Orthopaedics \& Related Research, 214, 249-262. http://dx.doi.org/10.1097/00003086-198701000-00036

[8] Dawson, I. and Van Rijn, A.B.B. (1989) Traumatic Anterior Dislocation of the Hip. Archives of Orthopaedic and Trauma Surgery, 108, 55-57. http://dx.doi.org/10.1007/BF00934160

[9] Endo, S., Yamada, Y., Fujii, N., Takakuwa, T., et al. (1993) Bilateral Traumatic Hip Dislocation in a Child. Archives of Orthopaedic and Trauma Surgery, 112, 155-156. http://dx.doi.org/10.1007/BF00449995

[10] Cash, D.J.W. and Nolan, J.F. (2007) Avascular Necrosis of the Femoral Head 8 Years after Posterior Hip Dislocation. Injury-Internal Journal of the Care Injured, 38, 865-867. http://dx.doi.org/10.1016/j.injury.2006.11.004

[11] Dreinhofer, K.E., Schwarzkopf, S.R., Haas, N.P. and Tscherne, H. (1994) Isolated Traumatic Dislocation of the Hip. Long-Term Results in 50 Patients. Journal of Bone \& Joint Surgery, 76, 6-12.

[12] Hougaard, K. and Thomsen, P.B. (1986) Traumatic Posterior Dislocation of the Hip: Prognostic Factors Influencing the Incidence of Avascular Necrosis of the Femoral Head. Archives of Orthopaedic and Trauma Surgery, 106, 32-35. http://dx.doi.org/10.1007/BF00435649

[13] Upadhyay, S. and Moulton, A. (1981) The Long Term Results of Traumatic Posterior Dislocation of the Hip. Journal of Bone \& Joint Surgery, 63, 548-551.

[14] Goulet, J.A. and Levin, P.E. (2008) Hip Dislocations. In: Browner, B.D., Ed., Skeletal Trauma, 3rd Edition, Saunders, New York, 1657-1691.

[15] Kuhn, D.A. and Frymoyer, J.W. (1987) Bilateral Traumatic Hip Dislocation. Journal of Trauma-Injury Infection \& Critical Care, 27, 442. http://dx.doi.org/10.1097/00005373-198704000-00019

[16] Patton, M.S., Banaskiewicz, P.A. and Finalayson, D. (2004) Traumatic Bilateral Posterior Dislocation of the Hip an Unusual Mechanism Resulting from an Agricultural Accident. Acta Orthopaedica Belgica, 70, 371-372.

[17] Lam, F., Walczak, J. and Franklin, A. (2001) Traumatic Asymmetrical Bilateral Hip Dislocation in an Adult. Emergency Medicine Journal, 18, 506-507. http://dx.doi.org/10.1136/emj.18.6.506

[18] Spagnolo, R., Matteo, B., Davide, G. and Dario, C. (2008) Posterior Bilateral Hip Dislocation with Ipsilateral acetabular Fracture. Injury-Internal Journal of the Care Injured, 39, 65-67.

[19] Jain, S., Haughton, B.A. and Grogan, R.J. (2015) Inferior Dislocation of the Hip: A Case Report and Literature Review. Journal of Orthopaedic Surgery, 23, 123-126.

[20] Singh, A.P. and Sidhu, A.S. (2010) Traumatic Bilateral Hip Dislocation with Bilateral Sciatic Nerve Palsy. Chinese Journal of Traumatology, 13, 126-128.

[21] Şahin, V., Karakaş, E.S., Aksu, S., Atlihan, D., et al. (2003) Traumatic Dislocation and Fracture-Dislocation of the Hip: A Long-Term Follow-Up Study. Journal of Trauma-Injury Infection \& Critical Care, 54, 520-529. http://dx.doi.org/10.1097/01.TA.0000020394.32496.52

[22] Glass, A. and Powell, H.D.W. (1961) Traumatic Dislocation of the Hip in Children: An Analysis of Forty-Seven Patients. Journal of Bone \& Joint Surgery, 43, 29.

[23] Schlickewei, W., Elsässer, B., Mullaji, A.B. and Kuner, E.H. (1993) Hip Dislocation without Fracture: Traction or Mobilization after Reduction? Injury-Internal Journal of the Care Injured, 24, 27-31. 